\title{
Comportamento alimentar e hábitos de vida de universitários com migrânea na pandemia da COVID-19
}

\author{
Hellen Maria Santos da Silva (D), Nathalia Herculano de Sousa (D), Acássia Benjamim Leal Pires (D), \\ Ana Patrícia Pascoal Queiroz de Araújo (D), Maria da Glória Canto de Sousa (D), \\ Alcylene Carla de Jesus dos Santos (iD, Luana de Oliveira Leite
}

Universidade do Estado da Bahia, Salvador, Bahia, Brasil.

\section{Introdução}

A migrânea é um tipo de cefaleia de origem multifatorial e é considerada uma doença incapacitante. A pandemia da COVID-19 provocou alterações nos hábitos de vida e padrão alimentar da população, que são importantes gatilhos para as crises migranosas.

\section{Objetivo}

Avaliar o impacto das mudanças no estilo de vida e alimentação impostas pela pandemia da COVID-19 quanto à ocorrência de enxaqueca em universitários.

\begin{abstract}
Material e Métodos
Estudo transversal, retrospectivo, com abordagem descritiva, realizado com acadêmicos de uma universidade de Salvador, Bahia, no período de 12/2020 a 06/2021. Os universitários foram convocados por meio do aplicativo Whatsapp ${ }^{\circledR}$ e, posteriormente, direcionados via link para acesso ao termo de consentimento livre e esclarecido, que foi preenchido, assim como o questionário, via aplicativo de gerenciamento de pesquisa. Esta pesquisa foi aprovada pelo Comitê de Ética em Pesquisa, sob parecer no 4.351.573. Os dados foram analisados por meio de estatística descritiva.
\end{abstract}

\section{Resultados}

Amostra constituída por 83 indivíduos, 89,2\% mulheres, 45,8\% sedentários, 51,8\% relataram aumento de peso nos últimos meses e $59 \%$ têm dificuldade para conciliar o sono. Antes da pandemia, 7,3\% relataram 7-14 dias de enxaqueca por mês e, após, identificou-se aumento para $24,1 \%$. Além disso, $36,1 \%$ dos acadêmicos associaram algum alimento às crises de enxaqueca, sendo os gatilhos mais comuns: café $(20,5 \%)$, chocolate $(14,5 \%)$, embutidos (12\%), bebidas alcóolicas (9,6\%) e açúcar (6\%). Diante dos resultados, percebe-se que a pandemia implicou no aumento do número de dias com enxaqueca por mês, o que pode estar associado às alterações alimentares, à disfunção do sono potencializada pela crise sanitária, aumento de peso nos últimos meses, assim como devido à prevalência de sedentarismo observada.

\section{Conclusão}

As mudanças no estilo de vida e no comportamento alimentar ocasionadas pela pandemia da COVID-19 repercutiu no aumento de dias com enxaqueca por mês em universitários.

Palavras-chave: Transtornos de enxaqueca, COVID-19, Comportamento alimentar, Estilo de vida. 